$\mathrm{DE}$

M E D I C I N A

T R O P I C A L

$\mathrm{DE}$

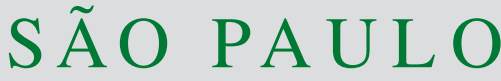

JOURNAL OF THE SÃO PAULO INSTITUTE OF TROPICAL MEDICINE

(1) Universidade Federal de Minas Gerais, Faculdade de Farmácia, Pós-Graduação em Medicamentos e Assistência Farmacêutica, Belo Horizonte, Minas Gerais, Brazil

(2) Universidade Federal de Minas Gerais, Faculdade de Medicina, Departamento de Clínica Médica, Belo Horizonte, Minas Gerais, Brazil

(3) Universidade Federal de Minas Gerais, Escola de Veterinária, Departamento de Medicina Veterinária Preventiva, Belo Horizonte, Minas Gerais, Brazil

(4) Universidade Federal de Minas Gerais, Faculdade de Farmácia, Departamento de Farmácia Social, Belo Horizonte, Minas Gerais, Brazil

Correspondence to: Wânia da Silva Carvalho Universidade Federal de Minas Gerais, Faculdade de Farmácia, Departamento de Farmácia Social, Av. Presidente Antônio Carlos, 6627, Sala 1060 B2, CEP 31270-901, Pampulha, Belo Horizonte, MG, Brazil

Tel: +55 31 3409-6860,

Fax: $+55313409-6852$

E-mail: waniasilvacarvalho@gmail.com

Received: 9 March 2016

Accepted: 22 February 2017

\section{Association of outcomes with comprehension, adherence and behavioral characteristics of tuberculosis patients using fixed-dose combination therapy in Contagem, Minas Gerais, Brazil}

\author{
Ana Maria Viegas ${ }^{1}$, Silvana Spíndola de Miranda², João Paulo Haddad ${ }^{3}$, Maria \\ das Graças Ceccato ${ }^{4}$, Wânia da Silva Carvalho ${ }^{4}$
}

\section{ABSTRACT}

The present study aimed to assess the association of outcomes with comprehension, adherence and behavioral characteristics of tuberculosis (TB) patients using fixed-dose combination (FDC) therapy in the city of Contagem, MG, Brazil. This study used standardized questionnaires to collect data. Outcomes included cure in $77.2 \%$ (64/ 83), noncompliance with treatment in $20.4 \%$ (17/ 83), and absence of organ failure or death cases. The rate of adherence to treatment was high $(71.1 \%$ - 59/ 83), while the level of comprehension of the treatment was insufficient for the majority of patients $(72.3 \%-60 / 83)$. When a greater number of medicines was used, the chance of noncompliance with treatment increased exponentially $(p=0.00$ - OR 1.72). Light-skinned black patients, alcoholics and those who live with HIV/ AIDS showed a significant association with noncompliance with treatment ( $\mathrm{p}=0.039$ - OR 3.38, $\mathrm{p}=0.002$ - OR 4.68, and $\mathrm{p}=0.001$ - OR 9.68, respectively). Comprehension also presented a significant association with noncompliance with treatment $(\mathrm{p}=0.01$ and $\mathrm{OR}$ 5.76 and CI 1.49-22.29). The probability of noncompliance with treatment in the first few months was greater than in the subsequent months. This study demonstrates that if the TB patients had a better understanding of the treatment, the outcome would have been more favorable as regards a proper cure.

KEYWORDS: Tuberculosis. Antibacterials. Comprehension.

\section{INTRODUCTION}

Tuberculosis (TB), considered a public health issue in its pulmonary clinical form, has been identified as the commonest form of new cases of the disease ${ }^{1}$. To confront this disease, one of the most important factors is an effective treatment. For this reason, Brazil has adopted procedures that aim to increase patients' adherence and reduce patients' noncompliance with treatment, thus increasing the cure rate of the disease ${ }^{2}$.

Patient noncompliance with TB treatment is a troublesome scenario and requires strategic measures to maintain a higher adherence to treatment ${ }^{3}$. Therefore, the success of the treatment depends heavily upon the proper embracement and followup of the patients by healthcare professionals ${ }^{4}$.

The knowledge or comprehension of the disease is of great importance in treatment adherence. Adverse reactions to medications, the treatment regimen, as well as treatment costs for patients and their families can influence the outcome leading to a higher noncompliance ${ }^{4,5,6}$. 
In 2009, the National Program for the Control of Tuberculosis (NPCT), introduced ethambutol as the fourth drug in the first stage of the basic therapy. Ethambutol was added due to the increase in primary resistance to $\mathrm{H}^{4}$. There was a change in the pharmacological presentation of the schema, which began with FDC tablets containing four drugs - Rifampicin, Isoniazid, Pyrazinamide, and Ethambutol (RHZE) in the intensive stage ${ }^{2,8}$. The World Health Organization (WHO) also recommends the use of FDC to increase TB treatment adherence ${ }^{9,10}$.

The present study aimed to assess the association of outcomes with comprehension, adherence and behavioral characteristics of tuberculosis (TB) patients using FDC therapy in the city of Contagem, MG, Brazil.

\section{METHODS}

This study was a prospective cohort aimed at evaluating the outcome of anti-TB treatment after the application of the new FDC (RHZE/ RH) drug therapy, conducted in Contagem, MG, Brazil. This study consisted of patients who were 18 years of age or older, with pulmonary or extra pulmonary TB, followed up at a primary care unit from November 2013 to April 2015, and defined as new cases. These patients were selected by the results registered in the TB laboratory information system or when they received the medicament to treat tuberculosis for the first time in regional pharmacies.

Patients submitted to retreatment outside the Primary Healthcare Unit (PHU) of Contagem, who died before the interview, were treated in other cities, and did not complete the treatment before the end of the study were excluded from this study.

The explanatory variables were collected by means of direct interviews conducted by the researcher using a standardized questionnaire. These variables included sociodemographic parameters (gender, age, education level) and socioeconomic characteristics (income); behavioral characteristics: use of illegal drugs; clinical characteristics (comorbidity); and Directly Observed Treatments (DOTS). To assess alcoholism, the CAGE (Cutdown, Annoyedby Criticism, Guilty and Eye-opener) questionnaire was applied $^{11}$.

Morisky scale of adherence to treatment was adapted to assess the adherence of patients to TB treatment, which uses eight questions with "Yes" or "No" answers. A total score of eight is considered high adherence, a score of less than eight but higher than six is considered average adherence, and a score below six is considered low adherence ${ }^{12}$. This questionnaire, aimed at assessing comprehension, was adapted for $\mathrm{TB}$, and the instrument used to assess the comprehension of treatment considers the answers sufficient when patients obtain $70 \%$ or more points and insufficient when the score is less than $70 \%$, 13 . This instrument was not applied to assess the comprehension of the use of other medicines, only to quantify them. This questionnaire was adapted from CIPOLLE to obtain the following variables: marital status, residency, smoking habits and side effects related to the drugs. ${ }^{14}$ All of the instruments were applied in three interviews during the patient's treatment, the first one being conducted at the end of the first month, the second one at the end of the second month, and the third one at the end of the sixth month.

The outcomes considered in this study included: cure, noncompliance with treatment, failure or death after the interview $^{7,15}$.

The descriptive analysis with the frequency distribution was conducted with categorical variables. For continuous variables, the evaluation of the core and dispersion tendencies (median, average and standard deviation) were assessed using the Statistics Analysis Package, STATA 12.1. The magnitude of the association was estimated by means of the odds ratio (OR). For all of the analyses the significance level was $p \leq 0.05$, with a confidence interval (CI) of $95 \%$.

A logistic regression analysis was conducted in two stages. The first stage was a selection of the explicative variables with potential of association between each variable and the outcome. The first stage was done using a logistic regression with three variables, the outcome, the explicative variable tested and the moment at which there was noncompliance with the treatment between the first and second interview. For the association study, between the outcomes and the explanatory variables, two subjects which died before the interview were excluded, so the outcome became a dichotomic variable (cure/ noncompliance with treatment). This kind of procedure was a univariate logistic regression model controlled by moment. The variables with p-values equal to or greater than 0.20 in the Wald test, in the univariate controlled analysis, were manually selected to begin the multivariate analysis with a stepwise process, with a backward selection. The multivariate analysis was used to assess the association between the explicative variables and the outcome response variable: cure and noncompliance with treatment.

The adjustment of the Hosmer \& Lemeshow model was also conducted. In this case, to demonstrate that the model was accepted, the null hypothesis should also be accepted, that is, $\mathrm{p}>0.05$.

This study was approved by the Research Ethics Committee from the Federal University of Minas Gerais (UFMG), under the protocol number CAAE 16298413.0.0000.5149. 


\section{RESULTS}

Eighty-three (83) patients were included in this study (Figure 1), of which 59.0\% (49/83) were male. Ages varied from 18 to 83 years, with an average age of 42.19 years (SD-15.0). The clinical form of TB was pulmonary in $84.3 \%$ (70/83) of the patients. The variables of sociodemographic, socioeconomic, behavioral and clinical characteristics, as well as those related to the drug therapy are in Table 1. Two patients were excluded because they did not complete the treatment before the end of the study.

The frequency of adherence to treatment was high $(80.8 \%$ - 67/ 83). In $10.8 \%$ (9/83), the adherence was average, while in $8.4 \%$ (7/ 83) it was low (Table 1).

All patients presented side effects; however, the majority $(97.5 \%)$ presented only a few reactions, and this variable had no effect on the patients' noncompliance with treatment (Table 1).

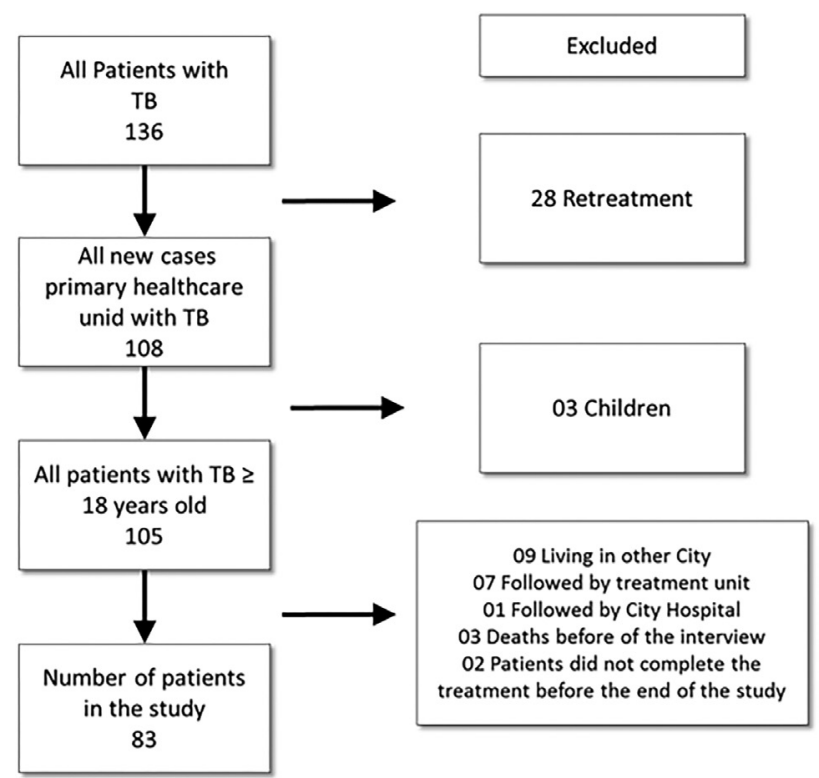

Figure 1 - Study sample

Table 1 - Descriptive analysis of the sociodemographic behavioral, clinical and pharmacotherapeutic characteristics $(n=83)$

\begin{tabular}{|c|c|c|c|}
\hline & Cured & $\begin{array}{l}\text { Noncom- } \\
\text { pliance }\end{array}$ & Death \\
\hline & $N(\%)$ & $\mathrm{N}(\%)$ & $\mathrm{N}(\%)$ \\
\hline \multicolumn{4}{|l|}{ SOCIODEMOGRAPHIC } \\
\hline \multicolumn{4}{|l|}{ Age (>18 years) } \\
\hline $18-41$ & $60(72.4)$ & $10(12.0)$ & 0 \\
\hline $\begin{array}{l}42-83 \\
\text { (Average 42.19) }\end{array}$ & \multicolumn{2}{|c|}{ (Average 42.19) } & $2(2.4)$ \\
\hline \multicolumn{4}{|l|}{ Gender } \\
\hline Male & $39(47.0)$ & $9(10.8)$ & $1(1.2)$ \\
\hline Female & $26(31.3)$ & $7(8.4)$ & $1(1.2)$ \\
\hline \multicolumn{4}{|l|}{ Housing } \\
\hline House /Apartment & $63(75.9)$ & $15(18.0)$ & $2(2.4)$ \\
\hline Shelter & $1(1.2)$ & $2(2.4)$ & 0 \\
\hline \multicolumn{4}{|l|}{ Race } \\
\hline Light-skinned black & $44(53.0)$ & $15(18.1)$ & $2(2.4)$ \\
\hline Other races & $20(24.1)$ & $2(2.4)$ & 0 \\
\hline \multicolumn{4}{|l|}{ Income } \\
\hline With Income & $48(57.8)$ & $10(12.1)$ & $2(2.4)$ \\
\hline Without Income & $16(19.3)$ & $7(8.4)$ & 0 \\
\hline \multicolumn{4}{|l|}{ Education level } \\
\hline$<08$ years & $48(57.8)$ & 13(15.7) & $1(1.2)$ \\
\hline$>08$ years & $16(19.3)$ & $4(4.8)$ & $1(1.2)$ \\
\hline \multicolumn{4}{|l|}{ CLINICAL } \\
\hline \multicolumn{4}{|l|}{ Form } \\
\hline Pulmonary & $52(62.7)$ & $16(19.3)$ & $2(2.4)$ \\
\hline Extrapulmonary & $12(14.4)$ & $1(1.2)$ & 0 \\
\hline \multicolumn{4}{|l|}{ Health problems } \\
\hline AIDS & $5(6.0)$ & $3(3.6)$ & 0 \\
\hline Diabetes & $7(8.4)$ & $2(2.4)$ & 0 \\
\hline Others & $27(32.6)$ & $5(6.0)$ & 2(2.4) \\
\hline No health problems & $26(31.4)$ & $6(7.2)$ & 0 \\
\hline
\end{tabular}

\begin{tabular}{lccc}
\hline & Cured & $\begin{array}{c}\text { Noncom- } \\
\text { pliance }\end{array}$ & Death \\
\cline { 2 - 4 } & $\mathrm{N}(\%)$ & $\mathrm{N}(\%)$ & $\mathrm{N}(\%)$ \\
\hline TS/DOTS & & & \\
Yes & $9(10.8)$ & $5(6.0)$ & 0 \\
No & $55(66.3)$ & $12(14.5)$ & $2(2.4)$ \\
\hline PHARMACOTHERAPEUTIC & & & \\
\hline Side effects & & & \\
$\quad$ Lesser & $64(77.1)$ & $15(18.1)$ & $2(2.4)$ \\
$\quad$ Greater & 0 & $2(2.4)$ & 0 \\
Non-TB Medicines & & & \\
$\quad$ Without use of medicines & $25(30.1)$ & $11(13.3)$ & 0 \\
01 medicine & $13(15.7)$ & $4(4.8)$ & 0 \\
$\quad$ 02 medicines or more & $24(28.9)$ & $4(4.8)$ & $2(2.4)$ \\
Adherence & & & \\
$\quad$ High & $51(61.5)$ & $14(16.9)$ & $2(2.4)$ \\
Average & $9(10.8)$ & 0 & 0 \\
$\quad$ Low & $4(4.8)$ & $3(3.6)$ & 0 \\
Understanding & & & \\
$\quad$ Sufficient & $18(21.7)$ & $3(3.6)$ & 0 \\
Insufficient & $46(55.4)$ & $14(16.9)$ & $2(2.4)$ \\
\hline BEHAVIORAL & & & \\
\hline Smoking & & & \\
Yes & $10(12.0)$ & $5(6.0)$ & 0 \\
$\quad$ No & $54(65.1)$ & $12(14.5)$ & $2(2.4)$ \\
Alcoholism & & & \\
Yes & $10(12.0)$ & $6(7.2)$ & 0 \\
$\quad$ No & $54(65.1)$ & $11(13.3)$ & $2(2.4)$ \\
Marital status & & & \\
$\quad$ Single/Divorced/Widow & $30(36.1)$ & $10(12.1)$ & 0 \\
$\quad$ Married/Stable Union & $34(41.0)$ & $7(8.4)$ & $2(2.4)$ \\
\hline
\end{tabular}


Patients presented full cure in $77.2 \%$ (64/ 83) of the cases and noncompliance with treatment in 20.4\% (17/ 83). There were no cases of organ failure or death caused by TB. Death after the interview by other causes was 2.4\% (2/ 83).

Age, gender, marital status, education level, smoking habits, having a regular income or not and supervised treatment proved to be unassociated with patients' noncompliance with treatment (Table 1).

The level of comprehension of TB treatment was insufficient for the majority of patients: $72.3 \%$ (60/ 83).

The use of other medications in addition to anti-TB drugs happened in $56.6 \%$ (47/83). When the patient used a large number of medications the probability of noncompliance with treatment increased exponentially (OR 1.72), with $\mathrm{p}=0.00$ (Table 2).

Light-skinned black patients, alcoholics and those who live with HIV/ AIDS presented a significant association with the noncompliance with TB treatment $(\mathrm{p}=0.03, \mathrm{p}=0.00$, and $\mathrm{p}=0.00$, respectively). The parameter comprehension has also presented a significant association with the noncompliance with treatment $(\mathrm{p}=0.01, \mathrm{OR} 5.76$, and CI 1.49-22.29), as shown in Table 2.

Figure 2 shows that the probability of patients' noncompliance with TB treatment in the first months is greater than in the subsequent months, and that the

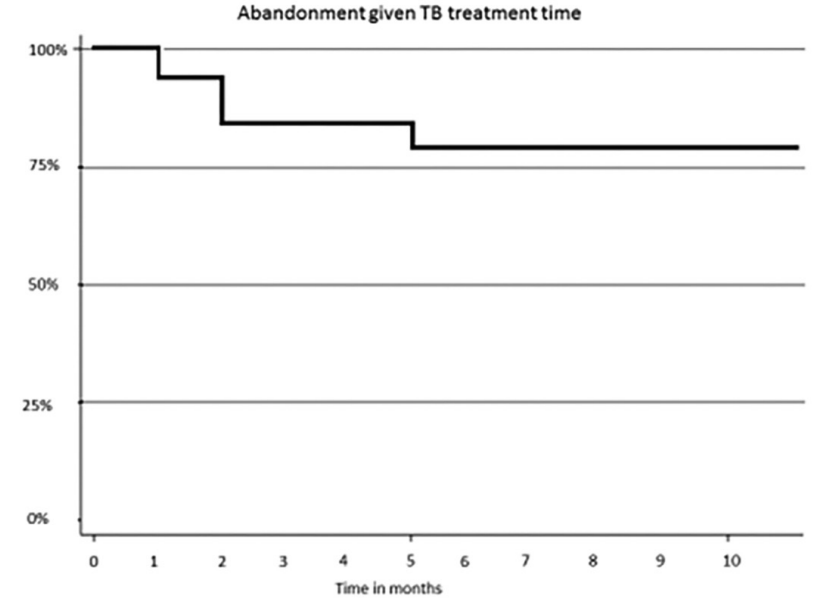

Figure 2 - Percentage of noncompliance with treatment according to the time of TB treatment

accumulated incidence was of $20.4 \%$ in the first two months. In $6.0 \%(5 / 83)$ of the patients who were noncompliant with the treatment, the noncompliance happened after the first interview, while in 10.8\% (9/83) it happened after the second interview.

\section{DISCUSSION}

In 2003, Contagem was classified by the Brazilian

Table 2 - Multivariate analysis of sociodemographic, behavioral, clinical and pharmacotherpeutic variables $(n=83)^{\star}$

\begin{tabular}{|c|c|c|c|c|c|}
\hline Variable/category & $\begin{array}{c}\text { Total } \\
\mathrm{n}=83(\%)\end{array}$ & OR Crude & OR Ajust & $\mathrm{Cl}$ & $\mathbf{P}$ \\
\hline \multicolumn{6}{|l|}{ Comprehension } \\
\hline Insufficient & $60(72.30)$ & 8.00 & 5.76 & $1.49-22.29$ & 0.01 \\
\hline Sufficient & $23(27.70)$ & & & & \\
\hline \multicolumn{6}{|l|}{ Income } \\
\hline Without income & $23(27.70)$ & 2.1 & 2.08 & $0.88-4.93$ & 0.09 \\
\hline With income & $60(72.30)$ & & & & \\
\hline \multicolumn{6}{|l|}{ Race } \\
\hline Light-skinned black & $60(72.30)$ & 3.40 & 3.38 & $1.06-10.77$ & 0.03 \\
\hline Other races & $23(27.70)$ & & & & \\
\hline \multicolumn{6}{|l|}{ Smoking } \\
\hline Yes & $15(18.10)$ & 2.25 & 1.52 & $0.60-3.85$ & 0.38 \\
\hline No & $68(81.90)$ & & & & \\
\hline \multicolumn{6}{|c|}{ Use of other non-anti-TB medicines } \\
\hline No use & $36(43.37)$ & & & & \\
\hline 01 medicine & $17(20.49)$ & 1.63 & 1.72 & $1.44-2.06$ & 0.00 \\
\hline 02 medicines or more & $30(36.14)$ & 2.78 & 2.94 & & \\
\hline \multicolumn{6}{|l|}{ Alcoholism } \\
\hline Yes & $16(19.30)$ & 2.95 & 4.68 & $1.74-12.61$ & 0.00 \\
\hline No & $67(80.70)$ & & & & \\
\hline \multicolumn{6}{|l|}{ AIDS } \\
\hline Yes & $8(9.60)$ & 2.53 & 9.68 & $2.63-35.70$ & 0.00 \\
\hline No & $75(90.40)$ & & & & \\
\hline
\end{tabular}

*The model was controlled as of the beginning of the interview. 
Health Ministry (BHM) as a priority city in the number of $\mathrm{TB}$ cases $^{7}$. In this city, the noncompliance with treatment is above that defined as acceptable by the WHO and the BHM, which is less than $5 \%$.

This study was conducted due to the change of TB treatment for FDC in 2009, considering that studies on the impact and outcome of new cases treated with FDC are scarce in the country.

The present study found that the cure rate was greater (77.2\%) when compared to data from 2008 (prior to application) (69.1\%), including all clinical forms; however, it has also proved to be quite inferior to that set forth by the WHO ( $85 \%$ cure rate for pulmonary TB cases $)^{4}$.

Noncompliance with treatment was similar (20.4\%) to the data from $2008(19.2 \%)$. The cure rate increased due to the reduction of deaths and organ failure, yet the noncompliance with treatment remained the same. Although other studies ${ }^{17,18,19}$ report similarities and divergences with the present study, none used primary data.

Although some sociodemographic, clinical and behavioral data in our study are not related to patients' noncompliance with treatment, other studies have shown this relationship regarding age, gender, marital status, residency, education level, having a regular income or not, DOTS and smoking habit (Table 1) 20,21,22,23. These studies used methods or analyses of results that were different from the ones used in the present study, which may well have generated divergences. In fact, the statistical analysis used in our study assessed the results considering the variables controlled by the moment of noncompliance with treatment between the first and second interviews regarding the parameter adherence, whose association with DOTS has been previously studied and demonstrated ${ }^{23,24}$.

FDC drug therapy is recommended by the WHO as an additional measure to increase patients' adherence to TB treatment ${ }^{9,10}$; however, other studies report that this formulation is not related to the noncompliance with treatment ${ }^{17}$.

The insufficient level of comprehension presented a significant association with patients' noncompliance with treatment. Therefore, it is necessary to invest in strategies that improve the quality of the guidelines provided to the patients. It is essential to encourage the communication of healthcare professionals with patients on an individual basis so that the patient will be able to understand the guidelines and the success of treatment. Note that the patients in this study received no incentives or any orientation about the disease.

The medical advice provided by healthcare professionals concerning the medicines and their correct use must be a priority. In addition, comprehension of the difficulties and facilities that patients face to understand their treatment will help healthcare professionals to develop educational strategies aimed at the therapeutic process. The study showed that if the TB patients had understood the treatment the results could have been more favorable concerning their full cure.

Although no other studies have shown the association between the use of other medicines, other than those for TB, with patients' noncompliance with treatment, in the present study, it was evident that each added medication increased the probability of noncompliance with treatment. However, some authors report that the association of various medicines interferes with the outcome ${ }^{25}$.

The side effects were the most commonly identified factor associated with noncompliance due to the method used in this study (interview), which shows the relevance and reliability of the information, given that the studies that reported only $20 \%$ and less side effects used secondary data and were not conducted with the entire population of a given city ${ }^{17}$.

The risk factors associated with noncompliance with treatment such as light-skinned blacks, alcoholics and patients who live with HIV/ AIDS, illustrate that these social and clinical questions are still important in an attempt to develop medical care actions geared toward these individuals, thus leading to TB control. Other authors have also observed this relationship as a predictor of noncompliance with treatment ${ }^{22}$.

As described by other authors ${ }^{22}$, the present study demonstrated that the probability of patients' noncompliance with treatment, especially in the first two months, is greater, since the patient feels better, believes that he/she is cured and that there is no further need to continue taking the medicine. This reiterates the importance of the patient's comprehension of the treatment. Thus, healthcare professionals should devote more time to the process of providing medical advice to patients, as well as in the follow up to guarantee all possible medical care to the patient. It is important to remember that these professionals should create ties with their patients so that the Health Unit can become a reference for these complications ${ }^{26}$.

The main limitation of this study was the lack of assessment of the comprehension and adherence to other medicines used to treat other medical conditions that could interfere in the results; however, this was not within the scope of this study.

It is therefore possible to conclude that the outcome of TB treatment after the application of the new FDC drug therapy in Contagem showed that the cure was below the recommended rate by WHO while noncompliance was above and that patients' comprehension was associated with their noncompliance with treatment. 


\section{REFERENCES}

1. Brasil. Ministério da Saúde. Secretaria de Vigilância em Saúde. Tuberculose: alinhada com o social, afinada com a tecnologia. Bol Epidemiol. 2013;44:1-6. Available from: http:// portalsaude.saude.gov.br/images/pdf/2014/maio/06/boletim22013-tb-web.pdf 2014.

2. Brasil. Ministério da Saúde. Secretaria de Vigilância em Saúde. Departamento de Vigilância Epidemiológica. Tratamento Diretamente Observado (TDO) da tuberculose na atenção básica: protocolo de enfermagem. Brasília: Ministério da Saúde; 2011.

3. Brasil. Ministério da Saúde. Secretaria de Vigilância em Saúde. Especial tuberculose. Bol Epidemiol. 2012;43:1-12. Available from: http://portalsaude.saude.gov.br/images/pdf/2014/ julho/23/BE-2012-43-Mar--o---Especial-Tuberculose.pdf

4. Brasil. Ministério da Saúde. Secretaria de Vigilância em Saúde. Departamento de Vigilância Epidemiológica. Manual de recomendações para o controle da tuberculose no Brasil. Brasília: Ministério da Saúde; 2011.

5. Ceccato MG, Acurcio FA, Bonolo PF, Rocha GM, Guimaraes MD. Compreensão de informações relativas ao tratamento anti-retroviral entre indivíduos infectados pelo HIV. Cad Saúde Pública. 2004;20:1388-97.

6. Orofino RL, Brasil PE, Trajman A, Schmaltz CA, Dalcolmo M, Rolla VC. Predictors of tuberculosis treatment outcomes. J Bras Pneumol. 2012;38:88-97.

7. Brasil. Ministério da Saúde. Secretaria de Políticas de Saúde. Plano nacional de mobilização e intensificação de ações para eliminação da hanseníase e controle da tuberculose. Brasília: Ministério da Saúde; 2001.

8. Brasil. Ministério da Saúde. Secretaria de Vigilância em Saúde. Informe técnico de tuberculose: novo sistema de tratamento da tuberculose para adultos e adolescentes no Brasil. Brasília: Ministério da Saúde; 2010.

9. World Health Organization. Treatment of tuberculosis guidelines. $4^{\text {th }}$ ed. Geneva: WHO; 2010. [cited 2016 Oct 11]. Available from: http://www.who.int/tb/publications/cds_tb_2003_313/en/

10. Conde MB, Melo FA, Marques AM, Cardoso NC, Pinheiro VG, Dalcin PT, et al. III Brazilian Thoracic Association Guidelines on tuberculosis. J Bras Pneumol. 2009;35:1018-48.

11. Mayfield D, Mcleod G, Hall P. The CAGE questionnaire: validation of a new alcoholism screening instrument. Am J Psychiatry. 1974;131:1121-3.

12. Moriski DE, Ang A, Kroussel-Wood M, Ward HJ. Predictive validity of a medication adherence measure in outpatient setting. J Clin Hypertens (Greenwich). 2008;10:348-54.

13. Silva T, Schenkel EP, Mengue SS. Nível de informação a respeito de medicamentos prescritos a pacientes ambulatoriais de hospital universitário. Cad Saúde Pública. 2000;16:449-55

14. Cipolle RJ, Strand LM, Morley PC. Pharmaceutical care practice: the clinician's guide. 2nd ed. New York: McGraw-Hill; 2004.

15. Moreno-Gómez M, Alonso-Sardón M, Iglesias-de-Sena H, Aranha de Macèdo LL, Mirón-Canelo JA. Seguimento prospectivo de los resultados del tratamiento antituberculoso. Rev Esp Quimioter. 2014;27:244-51.

16. Brasil. Ministério da Saúde. Fundação Nacional de Saúde. Tuberculose: guia de vigilância epidemiológica. Brasília: Ministério da Saúde; 2002.

17. Ferreira AC, Silva Júnior JL, Conde MB, Rabahi MF. Clinical treatment outcomes of tuberculosis treated with the basic regimen recommended by the Brazilian National Ministry of Health using fixed-dose combination tablets in the greater metropolitan area of Goiânia, Brazil. J Bras Pneumol. 2013;39:76-83.

18. Perrechi MC, Ribeiro SA. Outcomes of tuberculosis treatment among inpatients and outpatients in the city of São Paulo, Brazil. J BrasPneumol. 2011;37:783-90.

19. Behnaz F, Mohammadzadeh M, Mohammadzade G. Five-year assessment of time of sputum smears conversion and outcome and risk factors of tuberculosis patients in Central Iran. Tuberc Res Treat. 2015;2015:609083.

20. Pereira JC, Silva MR, Costa RR, Guimarães MD, Leite IC. Perfil e seguimento dos pacientes com tuberculose em município prioritário no Brasil. Rev Saúde Pública. 2015;49:6.

21. Naidoo P, Pelzer K, Louw J, Matseke G, Mchunu G, Tutshana B. Predictors of tuberculosis (TB) and antiretroviral (ARV) medication non-adherence in public primary care patients in South Africa: a cross sectional study. BMC Public Health. 2013;13:396.

22. Campani ST, Moreira JS, Tietbohel CN. Pulmonary tuberculosis treatment regimen recommended by the Brazilian National Ministry of Health: predictors of treatment noncompliance in the city of Porto Alegre, Brazil. J Bras Pneumol. 2011;37:77682.

23. Cruz MM, Cardoso GC, Abreu DM, Decotelli PV, Chrispim PP, Borenstein JS, et al. Adesão ao tratamento diretamente observado da tuberculose - sentido atribuído pelos usuários e profissionais de saúde em duas regiões administrativas do município do Rio de Janeiro. Cad Saúde Colet. 2012;20:21724.

24. Vieira AA, Ribeiro SA. Compliance with tuberculosis treatment after the implementation of the directly observed treatment, short-course strategy in the city of Carapicuíba, Brazil. J Bras Pneumol. 2011;37:223-31.

25. Gelaw BK, Mohammed A, Tegegne GT, Defersha AD, Fromsa M, Tadesse E, et al. Noadherence and contribuiting factors among ambulatory patients with antidiabetic medications in Adama Referral Hospital. J Diabetes Res. 2014;2014:617041.

26. Sultan H, Haroon S, Syed N. Delay and completion of tuberculosis treatment: a cross-sectional study in the West Midlands, UK. J Public Health (Oxf). 2012;35;12-20. 